\title{
Character displacement in sailfin mollies, Poecilia latipinna: allozymes and behavior
}

\author{
Caitlin R. Gabor ${ }^{\mathrm{a}}$, Michael J. Ryan ${ }^{\mathrm{b}}$ \& Donald C. Morizot ${ }^{\mathrm{c}}$ \\ ${ }^{a}$ Department of Biology, Texas State University, San Marcos, TX 7866, U.S.A. \\ (e-mail:gabor@txstate.edu) \\ ${ }^{\mathrm{b}}$ Section of Integrative Biology, C0930, University of Texas, Austin, TX 78712, U.S.A. \\ ${ }^{\mathrm{c}}$ The University of Texas M.D. Anderson Cancer Center, Science Park, Research Division, P.O. Box 389, \\ Smithville, TX 78957, U.S.A.
}

Received 2 December $2003 \quad$ Accepted 7 October 2004

Key words: genetic variation, livebearing fishes, Poecilia formosa, speciation

\section{Synopsis}

We analyzed variation in allozymes and mating preferences in 12 populations across much of the range of the sailfin molly, Poecilia latipinna. Sailfin mollies can be sympatric with its sexual parasite Amazon mollies, P. formosa. Amazon mollies must co-exist and mate with bisexual males of closely related species (including sailfin mollies) to induce embryogenesis but inheritance is strictly maternal. Where sailfin and Amazon mollies are sympatric there is evidence of reproductive character displacement as males show a significantly stronger mating preference for sailfin molly females over Amazon mollies compared to preferences of males from allopatric populations. From the allozyme data we found a moderate amount of genetic variation across all populations but this variation did not reveal significant partitioning between sympatric and allopatric populations. Additionally, we found no evidence for isolation by distance as genetic distance was not significantly correlated with geographic distance. While allozyme variation also did not significantly correlate with male mating preferences, there was a significant correlation between male mating preferences and geographic distance. This correlation between mating preferences and geographic distance may have arisen from coevolution with Amazon mollies resulting in reproductive character displacement. Taken together, the distribution of genetic and behavioral variation among sympatric and allopatric populations suggests that behavioral evolution has outpaced evolution at the allozyme loci we examined in P. latipinna.

\section{Introduction}

One process by which sexual selection can result in speciation is through reproductive character displacement. Reproductive character displacement is the divergence of a reproductive isolating trait of closely related species in areas of sympatry compared to areas of allopatry (Brown \& Wilson 1956, Howard 1993). Divergence can occur in either the signaling trait or the response to the signaling trait (Waage 1979), especially when the receivers suffer a greater fitness cost for errors in species recogni- tion (Gerhardt 1994). Although most studies of reproductive character displacement have concentrated on divergence of the signal, numerous studies have also documented reproductive character displacement of receivers as well (Gerhardt 1994, 1999, Noor 1995, Márquez \& Bosch 1997, Sætre et al. 1997, Rundle \& Schluter 1998, Marshall \& Cooley 2000, Pfennig 2000, Gabor \& Ryan 2001, Höbel \& Gerhardt 2003).

Although signals and receivers can exhibit greater divergence in populations sympatric with closely related species relative to signal-receiver divergence 
in allopatric populations, the degree of divergence can vary substantially within each biogeographical category. This is expected because throughout the range of a given species, local variation in signals and receivers could result from the interaction of gene flow and sexual selection. For example, aspects of signals or receivers that undergo character displacement in populations sympatric with closely related species could also be exhibited in nearby allopatric populations given sufficient gene flow. The latter scenario was suggested recently in green treefrogs, Hyla cinerea. Höbel \& Gerhardt (2003) found that one population in allopatry, but near the zone of sympatry with the closely related congener, $H$. gratiosa, had preferences similar to that of sympatric populations.

Models of clinal divergence in mating signals could account for situations in which allopatric populations exhibit mating preferences similar to preferences in sympatric populations, which appear to have evolved through reproductive character displacement. Lande (1982) argued that while there can be rapid displacement of a sexually selected signal that leads to divergence among populations, gene flow could also maintain a cline in signal variation. Thus an understanding of geographic patterns of species recognition traits requires some understanding of genetic interactions among populations.

Sailfin mollies have proven a useful species for investigating geographical variation in behavior and genetics. These livebearing fishes are found in the coastal plain of the Gulf of Mexico from northern Mexico to the southeastern coast of the United States. Trexler (1988) examined hierarchical genetic variation in 29 loci of 25 populations of sailfin mollies within Florida and Georgia and found that $75 \%$ of all allozyme variation was attributed to individuals within populations. Therefore, this system is characterized by substantial variation although there is little genetic structure among populations.

Many studies of behavioral variation in sailfin mollies have been motivated by the fact that they can be sympatric with Amazon mollies, a diploid unisexual (all female) species of fishes of hybrid origin that reproduce by gynogenesis (Hubbs \& Hubbs 1932). Amazon mollies must co-exist and mate with bisexual males of other species ( $P$. latipinna or $P$. mexicana) to induce embryogenesis, but inheritance is strictly maternal (Balsano et al. 1989). Amazon mollies occur in parts of southeastern Texas and northeastern Mexico and were introduced in San Marcos, Texas around the middle of the 19th century. Hereafter, we will use the terms 'sympatry' or 'sympatric population' to refer to sailfin molly populations that coexist with Amazon mollies and the terms 'allopatry' or 'allopatric populations' to refer to sailfin molly populations that do not coexist with Amazon mollies. Gabor \& Ryan (2001) examined male sailfin molly mating preference for sailfin females vs. Amazon mollies and found that males in six sympatric populations showed a significantly greater strength of preference for sailfin molly females than did males from five allopatric populations. These results along with previous work offer strong support for reproductive character displacement in male mating preferences in sailfin mollies (Ryan et al. 1996a, Gabor \& Ryan 2001). There was, however, substantial variation in the strength of conspecific preferences within sympatric and allopatric populations. Interestingly, one allopatric population exhibited preferences more characteristic of sympatric populations indicating that gene flow is potentially interacting with sexual selection. The primary goal of this study is to determine to what degree such variation among populations covaries with allozymes and thus might result from isolation by distance. Toward this goal we analyzed allozyme variation for 22 loci from the same 12 populations that Gabor \& Ryan (2001) used for the mating preference experiments.

We addressed four major questions: (1) Is genetic variation a product of isolation by distance? (2) Is genetic variation partitioned substantially between sympatric and allopatric populations? (3) Is genetic variation in male mating preference explained by genetic similarity? (4) Is variation in male mating preferences explained by isolation by distance?

\section{Materials and methods}

Allozymes

We used frozen tissue samples of 201 individuals of both sexes (collected between 1997 and 1998) 


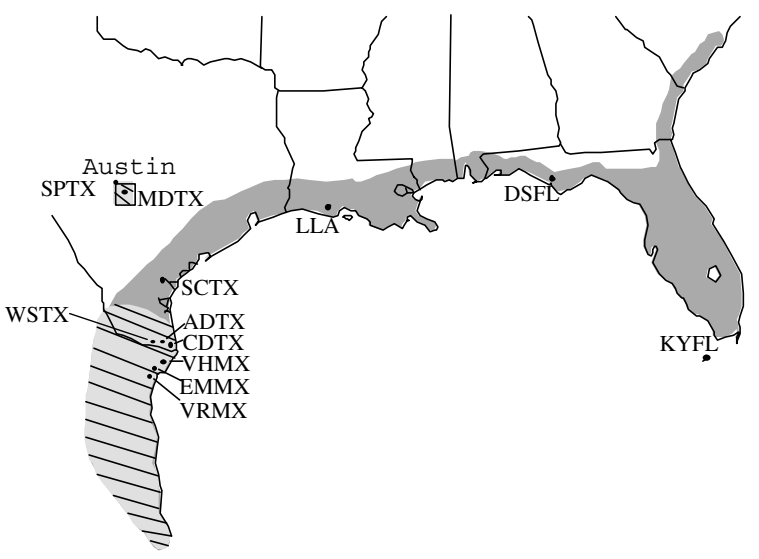

Figure 1. Distribution of sailfin mollies (Poecilia latipinna) and Amazon mollies ( $P$. formosa). The region of sympatry for sailfin and Amazon mollies is striped, the region of allopatry for sailfin mollies is shaded. The black dots indicate the collection sites. The black dot in the hatched square indicates the introduced Martindale, TX (MDTX) population. The test localities, starting from the farthest locality in Mexico and moving towards Austin, TX and then Florida Keys are as such: Villa Real, MX (VRMX); El Moquetito, MX (EMMX); Valle Hermosa, MX (VHMX); Central Ditch, TX (CDTX); Airport Ditch, TX (ADTX); Weslaco, TX (WSTX); Aquarena Springs, TX (SPTX); Salt Creek, TX (SCTX); Lafayette, LA (LLA); Destin, FL (DSFL); Florida Keys, FL (KYFL). The letters in parentheses are the abbreviated names for each population.

from 12 populations for starch gel allozyme electrophoresis (Figure 1, Table 1). We dissected brain, muscle, and eye tissue from each individual and stored the tissues at $-76^{\circ} \mathrm{C}$. We subjected tissue homogenates to horizontal starch gel electrophoresis following standard methods (Selander et al. 1971, Harris \& Hopkinson 1978,
Morizot \& Schmidt 1990). We surveyed 22 presumptive loci, of which 21 were reliably scoreable and 16 were polymorphic (Appendix 1). These 21 loci, listed with their abbreviations and their IUBNC Enzyme Commission numbers, are as follows: adenosine deaminase (ADA) (3.5.4.4), creatine kinase (CK) (2.7.3.2), carbonic anhydrase (CA, 2 loci) (4.2.1.1), esterase (EST, 2 loci) (3.1.1.1), glyceraldehydes-3-phosphate dehydrogenase (GAPD, 2 loci) (1.2.1.12), glucose-6-phosphate isomerase (GPI) (EC 5.3.1.9), L-lactate dehydrogenase ( $\mathrm{LDH}, 2$ loci) (1.1.1.27), malate dehydrogenase (MDH, 2 loci) (1.1.1.37), mannosephosphate isomerase (MPI, 2 loci) (5.3.1.8), nucleoside phosphorylase (NP) (2.4.2.1), peptidylprolyl isomerase (PPI) (5.2.1.8), 6-phosphogluconate dehydrogenase (6-PGD) (1.1.1.44), triosephosphate isomerase (TPI, 2 loci) (5.3.1.1), and muscle protein (MP, 2 loci).

We calculated measures of Nei's (1978) unbiased genetic distance and the cophenetic correlation for UPGMA using BIOSYS-1 release 1.7 software (Swofford \& Selander 1981). We examined evolutionary relationships among the 12 populations using phenetic and phylogenetic methods of the PHYLIP 3.572c software package (Felsenstein 1995). We constructed dendrograms based on Nei's (1978) unbiased genetic distances (from BIOSYS-1) with the program NEIGHBOR that employs UPGMA (Sneath \& Sokal 1973) and neighbor-joining methods. We performed maximum likelihood analysis with the program CONTML to construct a phylogeny based on population allele frequencies (Felsenstein 1995).

Table 1. Voucher specimens for the analysis of allozyme electrophoresis samples.

\begin{tabular}{llllc}
\hline Population & $\mathrm{n}$ & Locality & \multicolumn{2}{c}{ Latitude and Longitude (decimal degrees) } \\
\hline Florida Keys & 13 & Florida: Dade Co., Long Key & $24.82 \mathrm{~N}$ & $80.81 \mathrm{~W}$ \\
Destin & 21 & Florida: Walton Co., Choctawhatchee Bay & $30.44 \mathrm{~N}$ & $86.36 \mathrm{~W}$ \\
Lafayette & 19 & Louisiana: Lafayette Parish, Lafayette Electricity plant & $30.20 \mathrm{~N}$ & $92.02 \mathrm{~W}$ \\
Salt Creek & 18 & Texas: Aransas Co., Salt Creek River & $28.33 \mathrm{~N}$ & $97.24 \mathrm{~W}$ \\
Spring Lake & 19 & Texas: Hays Co., San Marcos River headwater & $29.89 \mathrm{~N}$ & $97.82 \mathrm{~W}$ \\
Martindale & 8 & Texas: Caldwell Co., San Marcos River & $29.91 \mathrm{~N}$ & $97.74 \mathrm{~W}$ \\
Weslaco & 20 & Texas: Cameron Co., Weslaco & $26.13 \mathrm{~N}$ & $97.92 \mathrm{~W}$ \\
Airport Ditch & 16 & Texas; Cameron Co., Brownsville & $25.93 \mathrm{~N}$ & $97.48 \mathrm{~W}$ \\
Central Ditch & 11 & Texas: Cameron Co., Brownsville & $25.89 \mathrm{~N}$ & $97.47 \mathrm{~W}$ \\
Valle Hermosa & 18 & Tamaulipas, Mexico & $25.39 \mathrm{~N}$ & $97.36 \mathrm{~W}$ \\
El Moquetito & 17 & Tamaulipas, Mexico & $25.29 \mathrm{~N}$ & $97.46 \mathrm{~W}$ \\
Villa Real & 21 & Tamaulipas, Mexico & $25.19 \mathrm{~N}$ & $97.56 \mathrm{~W}$ \\
\hline
\end{tabular}


We used bootstrapping (SEQBOOT and CONSENSE) for continuous maximum likelihood and neighbor joining analyses to determine support for the resolved clades out of 1000 replicates (Felsenstein 1995). We used midpoint rooting for all trees.

We subjected allele frequency data to principal components analysis using PCA-Gen ${ }^{1}$ to resolve relative similarities among populations without the constraints of forcing them into a set of bifurcations. Additionally, we used nonmetric multidimensional scaling (MDS; Kruskal \& Wish 1978, Lessa 1990) of Nei's (1978) genetic distances using the NCSS 2001 computer statistical package (NCSS Statistical Software, Kaysville, Utah) to illustrate the relationships among populations. This ordination technique allows for a visual inspection of clustering patterns and may be more appropriate than hierarchical analyses when reticulation or clinal patterns occur (Lessa 1990).

We used a nested analysis of variance (ANOVA) to examine partitioning of genetic variation among and within sympatric, allopatric, and introduced populations following the methods of Weir \& Cockerham (1984) and Weir (1996). We partitioned total sums of squares into nested hierarchical components representing variation among individuals within populations, among populations within groups (sympatric, allopatric, and introduced populations), and among groups using ARLEQUIN version 2.0 software (Schneider et al. 2000, unpublished). We determined significance of $\theta$-statistics and variance components using 1000 permutations of genotypes among populations and among groups (sympatric, allopatric, and introduced populations) under the null hypothesis of panmixia. To calculate the $F_{\mathrm{ST}}$ statistic we used $\theta_{\mathrm{CT}}$ from the nested analysis of variance and assumed an island model of equilibrium (Slatkin 1978).

We used a Mantel test (Smouse et al. 1986) to determine the correlations between populations in a pairwise matrix of genetic similarity, estimated as Nei's (1978) unbiased genetic distances, a pairwise matrix of geographic distance, estimated as geographic distance $(\mathrm{km})$ between localities after accounting for the Earth's curvature. We used Rpackage to obtain geographic distances between

\footnotetext{
${ }^{1}$ Available at http://www.unil.ch/izea/softwares/pcagen.html.
}

populations and for the Mantel tests (Legendre \& Vaudor 1991).

\section{Allozymes and behavior}

Insemination in sailfin mollies is internal and occurs when males thrust their gonopodium into the gonopore of females. Gabor \& Ryan (2001) tested 11 populations of male sailfin mollies to determine male mating preference for size matched sailfin vs. Amazon molly females from a twelfth sympatric population. For each male within each population they recorded the number of gonopodial thrusts directed by each male, in a $10 \mathrm{~min}$ period, at each species of female when the females were simultaneously presented. From these data Gabor \& Ryan (2001) calculated male strength of preference for conspecific females for each population as the proportion of the total gonopodial thrusts directed towards sailfin molly females. Using the data from the 11 populations of males tested by Gabor \& Ryan (2001) we created a pairwise matrix of the differences in the mean strength of preferences between all populations and compared it with a pairwise matrix of the genetic distances and a pairwise matrix of the geographic distance between these populations using a Mantel test. No males were tested from the twelfth sympatric population as Gabor \& Ryan (2001) only used the females from this population for the stimulus fish. We used a partial Mantel test to examine the relationship between the pairwise matrix of the difference in the mean strength of preference between populations, the pairwise matrix of geographic distance, and the pairwise matrix of genetic distance by calculating the relationship between two matrices while controlling for covariation in a third matrix. We performed the partial Mantel test for each of the three variables using the R-package with $\alpha=0.05$ (Legendre \& Vaudor 1991).

\section{Results}

Allozymes

Three major clusters of populations can be seen in the UPGMA dendogram. One consists of six populations that are sympatric with Amazon 
(a)

Genetic Distance (D)

$\begin{array}{lllllllll}0.1295 & 0.1133 & 0.0971 & 0.0809 & 0.0647 & 0.0485 & 0.0323 & 0.0162 & 0.000\end{array}$

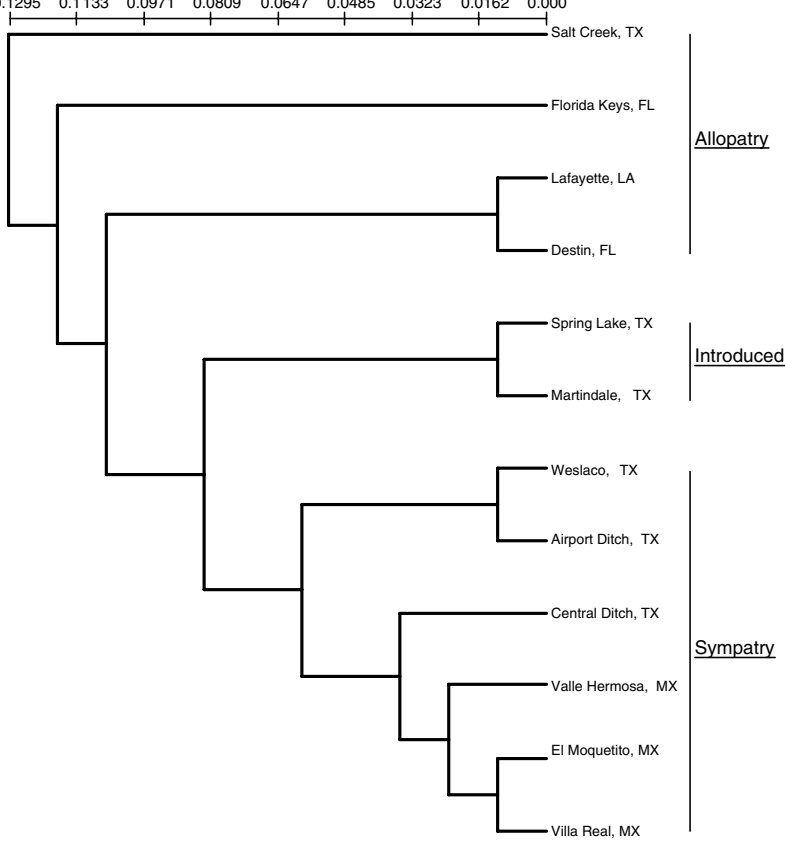

(b)

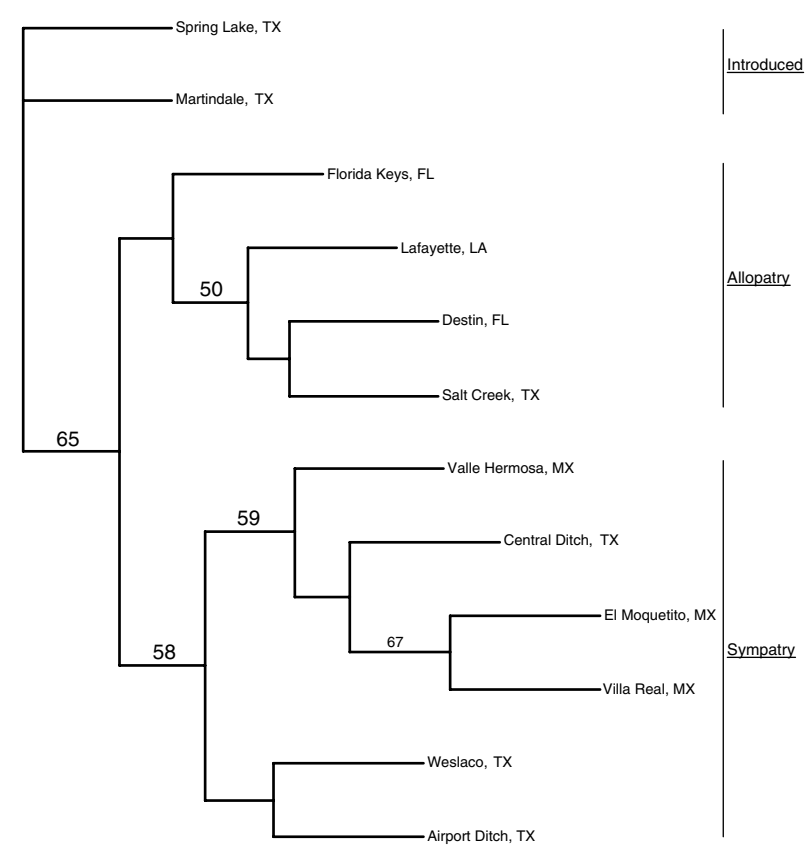

(c)

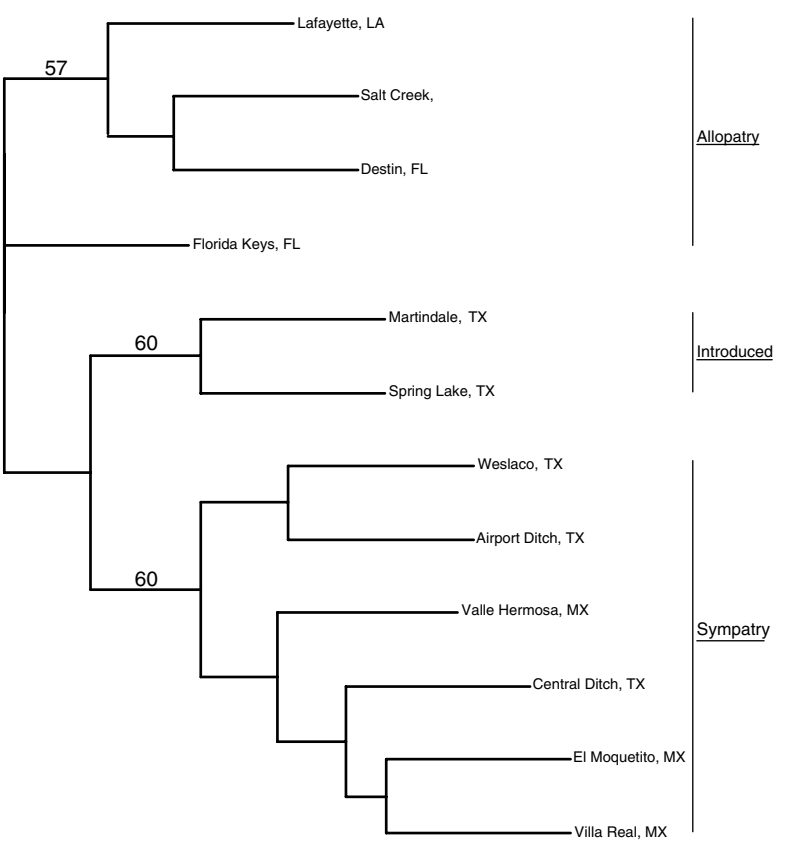

Figure 2. (a) UPGMA dendogram depicting the populations of $P$. latipinna examined in this study using Nei's (1978) unbiased genetic distance $(D)$. The cophenetic correlation is 0.952 . (b) Neighbor-joining phylogeny of $P$. latipinna. (c) Maximum likelihood phylogeny of $P$. latipinna. Bootstrap values (as percentages) from 1000 replicates are above the branches. 
mollies. Another cluster consists of two populations (Spring Lake, Texas and Martindale, Texas) that had been introduced from Louisiana and Florida in 1944 (Brown 1953). A third cluster consists of two populations that are allopatric with Amazon mollies. Florida Keys and Salt Creek, Texas (both allopatric populations) were the least similar populations (Figure 2a). The maximum likelihood and neighbor-joining trees (Figure 2b, c respectively) were congruent with each other and with the UPGMA tree except for Salt Creek, Texas. The results of the PCA showed a similar clustering of sympatric populations (Figure 3a). The first two axes of the principle component analysis explained $76.74 \%$ of the total genetic diversity and separated the sympatric populations from introduced sympatric and allopatric populations (except for the Salt Creek, Texas population). The introduced populations also clustered together, but the allopatric populations did not. The MDS analysis also revealed a cluster of sympatric populations and the introduced populations, while the allopatric populations were more dispersed with Salt Creek, Texas an outlier (Figure 3b, c). These groups are congruent with the geographic clusters of populations observed in the UPGMA dendograms and trees constructed by other methods described above (Figure 2). Interestingly EST-1 is alternately fixed with different alleles for the Florida Keys population, three other allopatric populations (Salt Creek, Texas; Lafayette, LA; Destin, Fl), and all of the sympatric populations (including the introduced sympatric populations).

Overall, a moderate amount of genetic variation was detected across all populations $(\bar{H} \pm \mathrm{SD}=0.104 \pm 0.056$; mean polymorphic loci $=29 \pm 7.7 \%$ ). Mean Nei's (1978) unbiased genetic distances between populations of $P$. latipinna was $\bar{D} \pm \mathrm{SD}=0.108 \pm 0.087 \quad$ (range $D=0.000-0.356)$. Nei's (1978) unbiased genetic distances and geographic distances $(\mathrm{km})$ between populations of $P$. latipinna are presented in Table 2 .

Nested analysis of variance did not reveal significant partitioning of genetic variation among sympatric and allopatric populations $\left(\theta_{\mathrm{CT}}\right.$ $=0.0139, p=0.185)$. The largest component of genetic variance was attributable to variation within populations (Table 3).
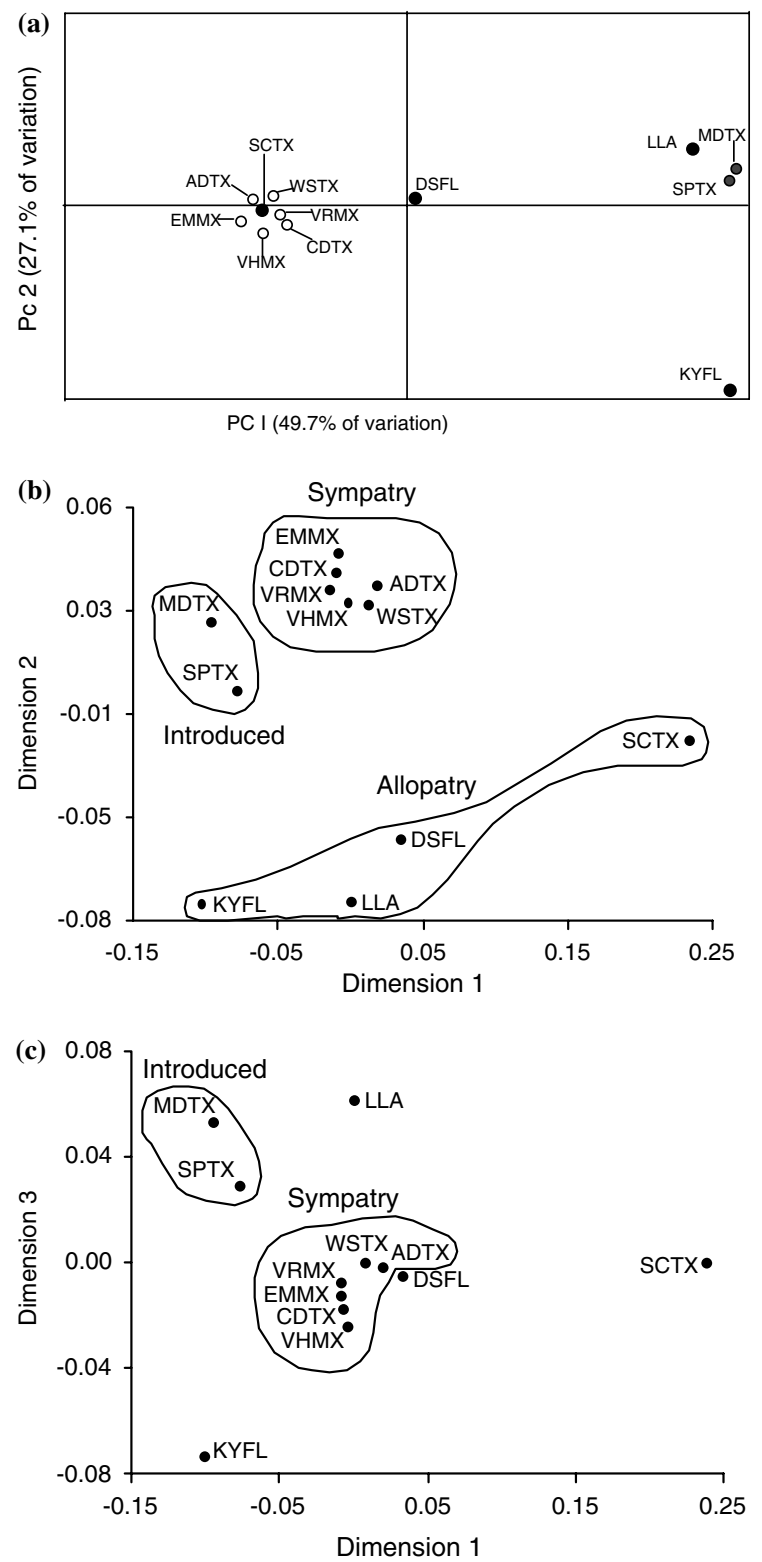

Figure 3. (a) Principle component analysis of allele frequency variation for all loci in 12 populations of Poecilia latipinna. Open circles are sympatric populations, filled circles, are allopatric populations. (b) Results of multidimensional scaling analyses, displayed as pairwise two dimensional scatterplots using dimension one vs dimension two. (c) MDS of dimension one vs. dimension three. The first two dimensions account for most of the differentiation and the first three dimensions account for virtually all of the differentiation. Population designations are the same as in Figure 1. 

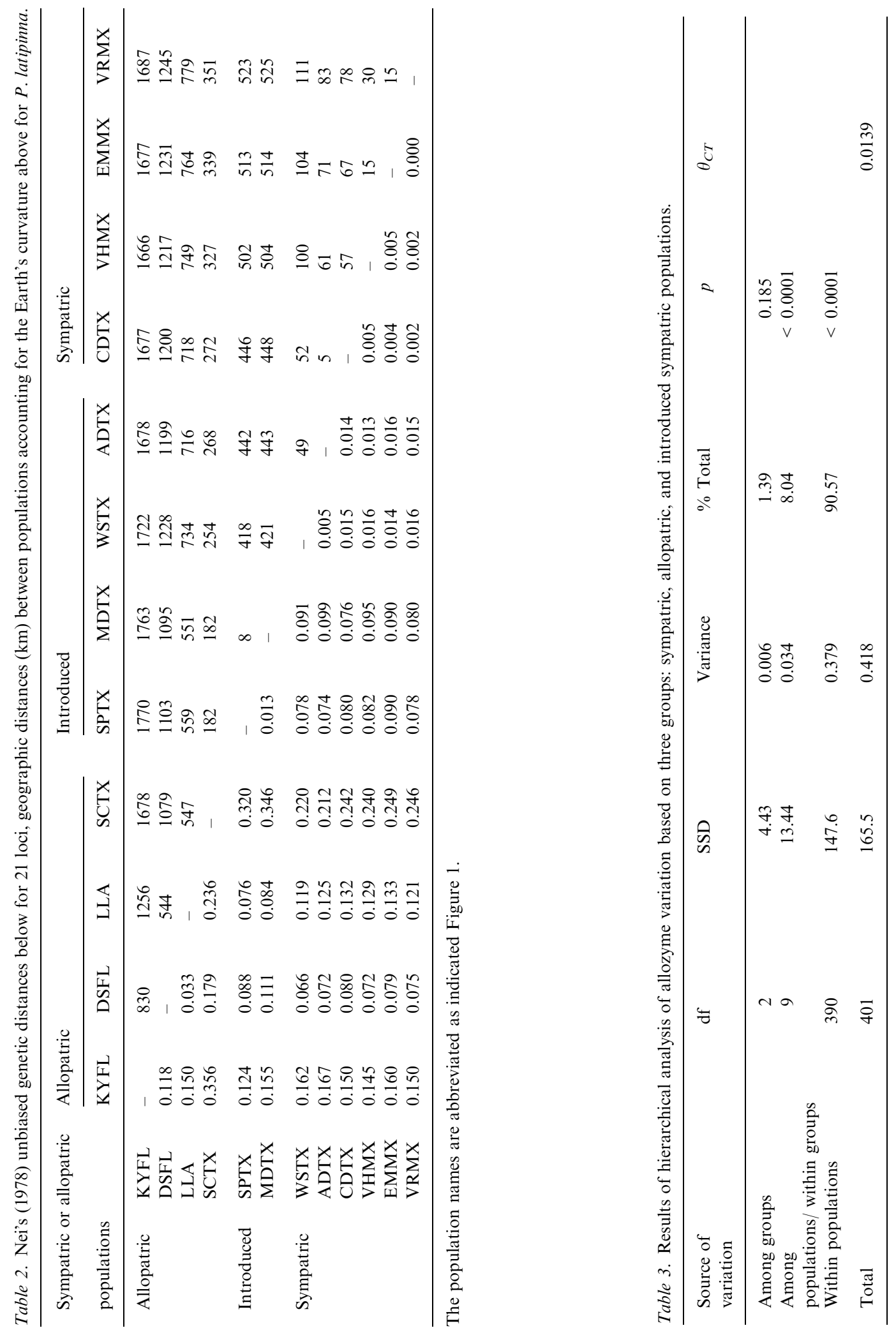

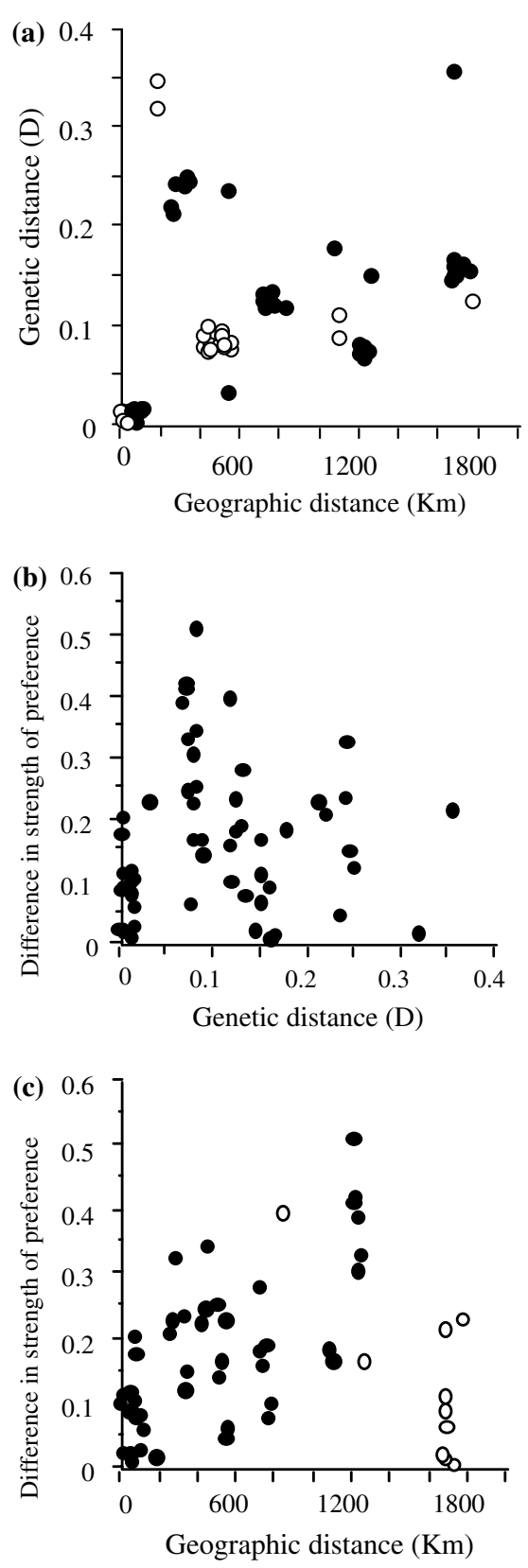

Figure 4. (a) Pairwise Nei's (1978) unbiased genetic distance (D) plotted against pairwise geographic distance $(\mathrm{km})$ for 12 populations of $P$. latipinna. (b) Pairwise differences in the mean strength of preference for $P$. latipinna females vs. $P$. formosa by male $P$. latipinna plotted against pairwise Nei's (1978) unbiased genetic distance $(D)$ for all tested populations. (c) Pairwise mean difference in strength of preference for $P$. latipinna females vs. $P$. formosa by male $P$. latipinna plotted against pairwise geographic distance $(\mathrm{km})$ for all tested populations. Dark circles are included in the analyses and open circles are excluded in some analyses.
Table 4. Simple and partial correlation coefficients and estimates of their statistical significance based on 9999 permutations.

\begin{tabular}{lcl}
\hline Coefficients (constant) & $r$-Value & $p$-Value \\
\hline $\begin{array}{l}\text { Genetic vs. geographic distance } \\
\begin{array}{l}\text { Strength of preference vs. genetic dis- } \\
\text { tance }\end{array}\end{array}$ & 0.336 & 0.11 \\
$\begin{array}{l}\text { Strength of preference vs. geographic } \\
\text { distance }\end{array}$ & 0.32 & 0.15 \\
$\begin{array}{l}\text { Genetic distance vs. strength of } \\
\text { preference (geographic distance) } \\
\text { Strength of preference vs. geographic } \\
\text { (genetic distance) }\end{array}$ & 0.221 & 0.16 \\
$\begin{array}{l}\text { Genetic vs. geographic distance } \\
\text { (strength of preference) }\end{array}$ & 0.388 & 0.11 \\
\hline
\end{tabular}

\section{Allozymes and behavior}

Genetic distance was not significantly correlated with geographic distance when all 12 populations were considered (Figure 4a, Table 4). When we repeated the analysis with the exclusion of introduced populations there was also no significant correlation $(r=0.464, p=0.100$; Figure 4a).

Variation in the mean strength of preference was not significantly correlated with genetic distance (Figure 4b, Table 4) or with geographic distance (Figure 4c, Table 4). In the latter analysis, however, the Florida Key population (an allopatric population with a significant preference for conspecific females (Gabor \& Ryan 2001)) was responsible for the non-significant results. When we excluded Florida Keys from the analysis there was a significant positive correlation between the variation in strength of preference and geographic distribution $(r=0.68, p=0.002)$. There was no significant covariation between strength of preference, geographic distance and genetic distance based on partial Mantel correlations when any one of the three variables was held constant (Table 4).

\section{Discussion}

Our examination of patterns of allozyme variation among populations offered no evidence for isolation by distance. Moreover, allozyme variation was not partitioned between populations sympatric and allopatric with Amazon mollies; 90\% of 
the variation was attributed to individuals within populations. These results are in accord with Trexler's (1988) studies of allopatric populations in Florida and Georgia where he attributed 75\% of the allozyme variation to individuals within populations. The strength of preference of male sailfin mollies for conspecific females was correlated with geographical distance, suggesting that there was isolation by distance but not variation in the particular allozymes we measured.

Taken together, the geographic distributions of genetic and behavioral variation among sympatric and allopatric populations suggest that behavioral change has responded more rapidly than evolution at the measured allozyme loci in P. latipinna. If the behavioral differences are heritable (i.e., not plastic responses to varying environments), they must have evolved relatively recently because there has been insufficient time since divergence for lineage sorting to occur at the allozyme level. That is, the variation observed from our allozyme survey likely represents ancestral polymorphism. Neigel \& Avise (1986) indicated that there is a period lasting roughly $4 N_{e}$ generations after the onset of divergence during which variation at neutral markers may not converge to the boundaries of the diverging evolutionary units (the populations in this case). Apparently, this time span has yet to be met.

The alternative to the hypothesis of recent divergence explaining the difference in genetic and behavioral variation is one of strong selection that maintains behavioral differences among allopatric and sympatric populations despite substantial gene flow. Assuming an island model and equilibrium, the average pairwise $F_{\text {st }}$ statistic among populations of $P$. latipinna $\left(F_{\mathrm{st}}=0.095\right)$ indicates $N_{\mathrm{m}}=2.38$ migrants per generation (Slatkin 1987). This value of migration is consistent with the results of Trexler (1988) who suggested that panmixia under a stepping-stone model was consistent with the analysis of his molly populations and thus stochastic process are an unlikely source of genetic differentiation. If the differences among sympatric and allopatric groups are adaptive, selection may maintain linkage disequilibrium between ecologically relevant genes and neutral markers. In fact, this disequilibrium between quantitative trait loci and neutral markers can be considered evidence of divergent selection (Whitlock 1999). Similar conclusions were made by Trexler (1988) within allo- patric population where local adaptation in sexual behavior persisted despite high gene flow.

The results of our allozyme analyses were consistent with other such studies. Of the 21 allozyme loci scored in 12 populations of $P$. latipinna five loci were monomorphic: CA-2, CK, PGD-1, TPI1, and TPI-2. CK was also monomorphic in the populations examined by Simanek (1978a) and Trexler (1988). PGD was monomorphic in the populations studied by Turner et al. (1980). MDH was virtually monomorphic at locus 1 , which is similar to Simanek (1978b) and Turner et al. (1980). We found a greater mean value of heterozygosity than both Simanek (1978a) and Trexler (1988). Our mean average value for polymorphic loci was intermediate between that found by Simanek (1978a) and Trexler (1988). Simanek $(1978 \mathrm{a}, \mathrm{b})$ found a mean heterozygosity of 0.066 across 14 populations (23 loci) in the United States, with an average of $43 \%$ polymorphic loci. Trexler (1988) found a mean heterozygosity of 0.07 for 25 populations (29 loci) in Florida and Georgia with an average of $14-20 \%$ polymorphic loci. Previous estimates of heterozygosity $(0.054$, Simanek 1978a; 0.047, Trexler 1988) near my samples from Florida Keys were somewhat different. The mean Nei's (1978) unbiased genetic distances between populations of $P$. latipinna was greater than found by Simanek (1978a) with $\bar{D}=0.064$ based on Rogers (1972).

The estimate of mean heterozygosity for sailfin mollies, $\bar{H}=0.063$, was slightly higher than that generally reported for fishes, which Nevo et al. (1984) reported as $\bar{H}=0.051$ and is within the range reported specifically for some livebearing fishes. Milstead (1980) found that the mean heterozygosity across 19 drainages throughout southeastern United States for Gambusia affinis was 0.055 with $49 \%$ polymorphic loci. Wootten et al. (1988) found that the mean heterozygosity for $G$. holbrooki was 0.113 and $59 \%$ of the loci were polymorphic. In contrast, the mean heterozygosity of $P$. formosa, which arose from hybridization of $P$. latipinna and $P$. mexicana, was $0.31-0.33$ (Turner et al. 1980). The average genetic distance between our populations was lower than reported for G. affinis, $\bar{D}=0.152$ and $G$. holbrooki, $\bar{D}=0.218$ based on Rogers (1972) distances (Wooten et al. 1988). This is not unexpected due to the high gene flow between our populations. 
Genetic variation between the populations of sailfin mollies is not a product of isolation by distance even when the two introduced populations were excluded. Genetic variation was also not partitioned among sympatry and allopatry. Prior studies on sailfin mollies found evidence for isolation by distance (Simanek 1978b, Trexler, 1988). It is not clear why our data differs from the other studies but it may have to do with the Salt Creek, Texas population being so divergent.

While genetic variation did not significantly correlate with variation in male mating preference, geographic distance did (when Florida Keys was removed). This suggests that variation in male mating preference cannot be inferred from allozyme data. Our previous study showed that males that have evolved longer with Amazon mollies (i.e., those from populations that were in deeper sympatry which is closer to the origin of Amazon mollies) showed greater strengths of preference for sailfin females. We are not certain why, however, the Florida Keys population varied so greatly from the others. Gabor \& Ryan (2001) suggested that the unexpected strong preference for conspecific females by allopatric sailfin males in Florida Keys might have been a result of differences in female responsiveness and not so much male preferences. We should also note that mate preferences could be learned which could explain the correlation with geographic distance, but there is no evidence for this.

The lack of covariance between geographic distance or genetic distance and strength of preference when any one of the three variables was held constant (based on a partial Mantel test) suggests that gene flow is not masking selection effects and is consistent with the hypothesis that sexual selection (or other selective forces) has induced patterns of local variation that disrupt clinal variation across the species' range as suggested by (Lande 1982). The fact that geography predicts male strength of preference also suggests that sexual selection is driving this divergence between the populations. Unless, as suggested by Ryan et al. (1996b) in their similar analyses of allozymes and call variation in Physalaemus pustulosus, these results are an outcome of the selected allozymes not indicating gene flow accurately. We recognize, additionally, that the sympatric populations are clustered geographically and that the allopatric populations are far apart and sparse and that this might influence this outcome. The reason this occurred was because we could not collect fishes from deeper sympatry due to severe drought conditions in the more southern populations of Mexico.

Historical biogeography of sailfin and Amazon mollies is not well resolved. As summarized by Schlupp et al. (2002; also see Darnell \& Abramoff 1968, Schartl et al. 1995), the hybridization event between $P$. mexicana and $P$. latipinna that gave rise to $P$. formosa occurred 100,000 year ago in the Rio Tampico in northeastern Mexico. It is not known, however, if sailfin and Amazon mollies spread northward from Mexico together, of if sailfins already occupied their current range prior to the existence of Amazons, who then spread northward after their founding hybridization in northern Mexico. While little is known about mollies, more is known about a similar livebearing fish species, the hemicolonal, Poeciliopsis. Poeciliopsis divided about 8-16 million years ago (Mateos \& Vrijenhoek 2002). The hybridogen, Poeciliopsis monacha-occidentalis based on mitochondrial evidence may be 150,000 years old (Quattro et al. 1992) and lives throughout Sonora, Mexico and mates with males of the sexual species $P$. occidentalis. A similar history may hold for Amazon mollies.

In conclusion, most studies have examined geographic variation in mate-recognition signals across hybrid zones (grasshoppers: Ritchie et al. 1992: fire-bellied toads: Sanderson et al. 1992; frogs: Littlejohn \& Robertson 1975, Höbel \& Gerhardt 2003) between species, but less so within species (crickets: Ferreira \& Ferguson 2002; frogs: Ryan \& Wilczynski 1991, Ryan et al. 1996b; jewel wasps: Bordenstein et al. 2000). Others have examined sexual isolation between species and genetic variation (Drosophila: Coyne \& Orr 1989, 1997; salamanders: Tilley et al. 1990; darter fish: Mendelson 2003). But none that we know of have examined geographical variation in allozymes and a receivers' mating preferences. Our results indicate that behavior has changed faster than allozymes. This may be a result of strong selective pressures from the parasitic unisexual Amazon mollies starting about 100,000 years ago (Avise et al. 1991, Schartl et al. 1995) that has consequently resulted in reproductive character displacement in male mating preferences between 
sympatric and allopatric populations (Ryan et al. 1996a, Gabor \& Ryan 2001).

\section{Acknowledgements}

We thank A. Aspbury, L. Dries, L. Higgins, C. Nice, and J. Ott for helpful discussion concerning this research. L. Dries, L. Higgins, J. Krejca, C. Papp, and I. Schlupp are thanked for helping to collect fishes. We also thank F. Aboudi and J. Stahl for preparing fishes for allozyme analyses and $\mathbf{J}$. Cruchfield at Brackenridge Field Laboratory for use of their facilities for maintaining fishes. Research was fully supported by funds from National Science Foundation Post-doctoral Research Fellowship grant DBI-9750278 to C.R.G. C.R.G. was also supported by Texas Higher Education Coordinating Board Advanced Research Program grant \# 003615-0004-2001 during manuscript preparation. We also thank the Mexican Government for permission to collect these fishes.

\section{References}

Avise, J.C., J.C. Trexler, J. Travis \& W. Nelson. 1991. Poecilia mexicana is the recent female parent of the unisexual fish $P$. formosa. Evolution 45: 1530-1533.

Balsano, J.S., E.M. Rasch \& P.J. Monaco. 1989. The evolutionary ecology of Poecilia formosa and its triploid associates. pp. 277-297. In: G.K. Meffe \& F.F. Snelson (eds.), Ecology and Evolution of Livebearing Fishes (Poeciliidae), Prentice Hall, New Jersey.

Bordenstein, S.R., M.D. Drapeau \& J.H. Werren. 2000. Intraspecific variation in sexual isolation in the jewel wasp Nasonia. Evolution 54: 567-573.

Brown, W.H. 1953. Introduced fish species of the Guadalupe River Basin. Texas J. Sci. 5: 245-251.

Brown, W.L. \& E.O. Wilson. 1956. Character displacement. Syst. Zool. 5: 49-64.

Coyne, J.A. \& H.A. Orr. 1989. Patterns of speciation in Drosophila. Evolution 43: 362-381.

Coyne, J.A. \& H.A. Orr. 1997. Patterns of speciation in Drosophila revisited. Evolution 51: 295-303.

Darnell, R.M. \& P. Abramoff. 1968. Distribution of the gynogenetic fish, Poecilia formosa, with remarks on the evolution of the species. Copeia 1968: 354-361.

Felsenstein, J. 1995. PHYLIP: Phylogenetic Inference Package, Version 3.572, University of Washington, Seattle, Washington, USA.

Ferreira, M. \& J.W.H. Ferguson. 2002. Geographic variation in the calling song of the field cricket Gryllus bimaculatus
(Orthoptera: Gryllidae) and its relevance to mate recognition and mate choice. J. Zool. 257: 163-170.

Gabor, C.R. \& M.J. Ryan. 2001. Geographical variation in reproductive character displacement in mate choice by male sailfin mollies. Proc. Roy. Soc. Ser. B. Biol. Sci. 268: 1063-1070.

Gerhardt, H.C. 1994. Reproductive character displacement of female mate choice in the grey treefrog, Hyla chrysoscelis. Anim. Behav. 47: 959-969.

Gerhardt, H.C. 1999. Reproductive character displacement and other sources of selection on acoustic communication systems. pp. 515-534. In: M.D. Hauser \& M. Konishi (eds.), The Design of Animal Communication, Massachusetts Institute of Technology Press, Boston, MA.

Harris, H. \& D.A. Hopkinson. 1978. Handbook of Enzyme Electrophoresis in Human Genetics. North-Holland Publishing Company, Amsterdam, Holland.

Höbel, G. \& H.C. Gerhardt. 2003. Reproductive character displacement in the acoustic communication system of green tree frogs (Hyla cinerea). Evolution 57: 894-904.

Howard, D.J. 1993. Reinforcement: origin, dynamics and fate of an evolutionary hypothesis. pp. 46-69. In: R.G. Harrison (ed.), Hybrid Zones and the Evolutionary Process, Oxford University Press, New York.

Hubbs, C. \& L.C. Hubbs. 1932. Apparent parthenogenesis in nature in a form of fish of hybrid origin. Science 76: $628-630$.

Kruskal, J.P. \& M. Wish. 1978. Multidimensional Scaling. Sage Publications, Newbury Park, California, USA.

Lande, R. 1982. Rapid origin of sexual isolation and character divergence in a cline. Evolution 36: 213-223.

Legendre, P. \& A. Vaudor. 1991. The R-package: Multidimensional Analysis, Spatial Analysis, University of Montreal, Québec, Canada.

Lessa, E.P. 1990. Multidimensional analysis of geographic genetic structure. Syst. Zool. 39: 242-252.

Littlejohn, M.J. \& J.D. Robertson. 1975. Acoustic analysis of an intergrade zone between two call races of the Limnodynastes tasmaniensis complex (Anura: Leptocactylidae) in southeastern Australia. Aust. J. Zool. 23: 113-122.

Márquez, R. \& J. Bosch. 1997. Male advertisement call and female preference in sympatric and allopatric midwife toads. Anim. Behav. 54: 1333-1345.

Marshall, D.C. \& J.R. Cooley. 2000. Reproductive character displacement and speciation in periodical cicadas, with description of a new species, a 13-year Magicicada neotredecima. Evolution 54: 1333-1345.

Mateos, M. \& R.C. Vrijenhoek. 2002. Ancient versus reticulate origin of a hemiclonal lineage. Evolution 56: 985-992.

Mendelson, T.C. 2003. Sexual isolation evolves faster than hybrid inviability in a diverse and sexually dimorphic genus of fish (Percidae: Etheostoma). Evolution 57: 317-327.

Milstead, E. 1980. Genetic differentiation among subpopulations of three Gambusia species (Pisces: Poeciliidae) in the Pecos River, Texas and New Mexico. M.S. thesis, Baylor University, Waco, Texas.

Morizot, D.C. \& M.E. Schmidt. 1990. Starch gel electrophoresis and histochemical visualization of proteins. pp. 23-80. In: D.H. Whitmore (ed.), Electrophoretic and Isoelectric 
Focusing Techniques in Fisheries Management, CRC Press, Boca Raton, FL.

Nei, M. 1978. Estimation of average heterozygosity and genetic distance from a small number of individuals. Proc. Nat. Acad. Sci. USA 70: 3321-3323.

Neigel, J.E. \& J.C. Avise. 1986. Phylogenetic relationships of mitochondrial DNA under various demographic models of speciation. pp. 515-534. In: E. Nevo \& S. Karlin (eds.), Evolutionary Processes and Theory, Academic Press, New York.

Nevo, E., A. Beiles \& R. Ben-Shlomo. 1984. The evolutionary significance of genetic diversity: ecological, demographic and life history correlates 53: 13-213. In: S. Levin (ed.), Lecture Notes in Biomathematics: Evolutionary Dynamics of Genetic Diversity, Springer-Verlag, Berlin.

Noor, M.A. 1995. Speciation driven by natural selection in Drosophila. Nature 375: 674-675.

Pfennig, K.S. 2000. Female spadefoot toads compromise on mate quality to ensure conspecific matings. Behav. Ecol. 11: 220-227.

Quattro, J.M., J.C. Avise \& R.C. Vrijenhoek. 1992. An ancient clonal lineage in the fish genus Poeciliopsis (Atheriniformes: Poeciliidae). Proc. Nat. Acad. Sci. USA 89: 348-352.

Ritchie, M.G., R.K. Butlin \& G.M. Hewitt. 1992. Fitness consequences of potential assortative mating inside and outside a hybrid zone in Chorthippus parallelus (Orthoptera: Acrididae): Implications for reinforcement and sexual selection theory. Biol. J. Linn. Soc. 45: 219-234.

Rogers, J.S. 1972. Measures of genetic similarity and genetic distance. Studies in Genetics, University of Texas Publishers 7213: 145-153.

Rundle, H.D. \& D. Schluter. 1998. Reinforcement of stickleback mate preferences: sympatry breeds contempt. Evolution 52: 200-208

Ryan, M.J., \& W. Wilczynski. 1991. Evolution of intraspecific variation in the advertisement call of a cricket frog (Acris crepitans, Hylidae). Biol. J. Linn. Soc. 44: 249-271.

Ryan, M.J., L.A. Dries, P. Batra \& D.M. Hillis. 1996a. Male mate preferences in a gynogenetic species complex of Amazon mollies. Anim. Behav. 52: 1225-1236.

Ryan, M.J., A.S. Rand \& L.A. Weigt. 1996b. Allozyme and advertisement call variation in the Túngara frog, Physalaemus pustulosus. Evolution 50: 2435-2453.

Sætre, G.-P., T. Moum, S. Bures, M. Král, M. Adamjan \& J. Moreno. 1997. A sexually selected character displacement in flycatchers reinforces premating isolation. Nature 387: $589-592$

Sanderson, N., J.M. Szymura \& N.H. Barton. 1992. Variation in mating call across the hybrid zone between the fire-bellied toads Bombina bombina and B. variegata. Evolution 46: 595-607.

Schartl, M., B. Wilde, I. Schlupp \& J. Parzefall. 1995. Evolutionary origin of a parthenoform, the Amazon molly, Poe- cilia formosa, on the basis of a molecular genealogy. Evolution 49: 827-835.

Schlupp, I., J. Parzefall \& M. Schartl. 2002. Biogeography of the Amazon molly, Poecilia formosa. J. Biogeogr. 29: $1-6$.

Schneider, S., D. Roessli \& L. Excoffier. 2000. Arlequin version 2.00: A software for populations genetics data analysis, Genetics and Biometry Laboratory, University of Geneva, Switzerland.

Selander, R.K., M.H. Smith, S.Y. Yang, W.E. Johnson \& J.B. Gentry. 1971. Biochemical polymorphism and systematics in the genus Peromyscus. I. Variation in the old-field mouse (Peromyscus polionotus). Studies in Genetics VI. University of Texas Publications 7103: 49-90.

Simanek, D.E. 1978a. Genetic variability and population structure of Poecilia latipinna. Nature 276: 612-614.

Simanek, D.E. 1978b. Population genetics and evolution in the Poecilia formosa complex (Pisces: Poeciliidae). Ph.D. dissertation, Yale University, New Haven.

Slatkin, M. 1987. Gene flow and the geographic structure of natural populations. Science 236: 787-792.

Smouse, P.E., J.C. Long \& R.R. Sokal. 1986. Multiple regression and correlation extensions of the Mantel test of matrix correspondence. Syst. Zool. 35: 627-632.

Sneath, P.H.A. \& R.R. Sokal. 1973. Numerical Taxonomy. W. B, Freeman, San Francisco, California.

Swofford, D.L. \& R.B. Selander. 1981. BIOSYS-1: A FORTRAN computer program for the comprehensive analysis of electrophoretic data in population genetics and systematics. J. Hered. 72: 281-283.

Tilley, S.G., P.A. Verrell \& S.J. Arnold. 1990. Correspondence between sexual isolation and allozyme differentiation: a test in the salamander Desmognathus ochrophaeus. Proc. Nat. Acad. Sci. USA 87: 2715-2719.

Trexler, J.C. 1988. Hierarchical organization of genetic variation in the sailfin molly, Poecilia latipinna (Pisces: Poeciliidae). Evolution 42: 1006-1017.

Turner, B.J., B.H. Brett, E.M. Rasch \& J.S. Balsano. 1980. Evolutionary Genetics of a Gynogenetic Fish, Poecilia formosa, the Amazon Molly. Evolution 34: 246-258.

Waage, J.K. 1979. Reproductive character displacement in Calopteryx (Odonata: Calopterygidae). Evolution 33: 104-116.

Weir, B.S. 1996. Genetic Data Analysis II. Sinauer and Associates, Sunderland, Massachusetts.

Weir, B.S. \& C.C. Cockerham. 1984. Estimating F-statistics for the analysis of population structure. Evolution 38: 1358-1370.

Whitlock, M.C. 1999. Neutral additive genetic variance in a metapopulation. Genet. Res. 74: 215-221.

Wootten, R.J., K.T. Scribner \& M.H. Smith. 1988. Genetic variability and systematics of Gambusia in the southeastern United States. Copeia 1988: 283-289. 
Appendix 1. The distribution of alleles among the 12 populations sampled in the analysis of overall geographic variation in P. latipinna. Letters designate alleles. $\bar{H}=$ mean heterozygosity, $\mathrm{A} / \mathrm{L}=$ mean number of alleles per locus, and $\% \mathrm{P}=$ percent loci polymorphic. The population names are abbreviated as indicated in Figure 1.

\begin{tabular}{|c|c|c|c|c|c|c|c|c|c|c|c|c|}
\hline \multirow[t]{2}{*}{ Locus } & \multicolumn{12}{|c|}{ Populations } \\
\hline & KYFL & DSFL & LLA & SCTX & SPTX & MDTX & WSTX & ADTX & CDTX & VHMX & EMMX & VRMX \\
\hline \multicolumn{13}{|l|}{ ADA } \\
\hline (n) & 13 & 21 & 19 & 18 & 19 & 8 & 19 & 16 & 11 & 18 & 17 & 21 \\
\hline A & 0.000 & 0.000 & 0.079 & 0.000 & 0.000 & 0.000 & 0.000 & 0.000 & 0.000 & 0.000 & 0.000 & 0.000 \\
\hline B & 0.000 & 0.000 & 0.000 & 0.028 & 0.000 & 0.000 & 0.000 & 0.000 & 0.000 & 0.000 & 0.000 & 0.000 \\
\hline $\mathrm{C}$ & 0.000 & 0.071 & 0.000 & 0.000 & 0.000 & 0.000 & 0.000 & 0.031 & 0.000 & 0.000 & 0.000 & 0.000 \\
\hline $\mathrm{D}$ & 1.000 & 0.929 & 0.921 & 0.972 & 1.000 & 1.000 & 1.000 & 0.969 & 1.000 & 1.000 & 1.000 & 1.000 \\
\hline \multicolumn{13}{|l|}{ CA-1 } \\
\hline (n) & 7 & 21 & 22 & 19 & 18 & 8 & 21 & 17 & 12 & 20 & 19 & 22 \\
\hline A & 0.214 & 0.000 & 0.000 & 0.000 & 0.000 & 0.000 & 0.000 & 0.000 & 0.042 & 0.025 & 0.079 & 0.023 \\
\hline $\mathrm{B}$ & 0.571 & 1.000 & 1.000 & 0.921 & 0.694 & 1.000 & 1.000 & 1.000 & 0.917 & 0.975 & 0.921 & 0.932 \\
\hline $\mathrm{C}$ & 0.000 & 0.000 & 0.000 & 0.000 & 0.000 & 0.000 & 0.000 & 0.000 & 0.000 & 0.000 & 0.000 & 0.000 \\
\hline $\mathrm{D}$ & 0.214 & 0.000 & 0.000 & 0.079 & 0.306 & 0.000 & 0.000 & 0.000 & 0.042 & 0.000 & 0.000 & 0.045 \\
\hline \multicolumn{13}{|l|}{ CA-2 } \\
\hline (n) & 15 & 21 & 22 & 16 & 19 & 8 & 20 & 16 & 12 & 20 & 19 & 22 \\
\hline A & 1.000 & 1.000 & 1.000 & 1.000 & 1.000 & 1.000 & 1.000 & 1.000 & 1.000 & 1.000 & 1.000 & 1.000 \\
\hline \multicolumn{13}{|l|}{$\mathrm{CK}$} \\
\hline (n) & 13 & 21 & 18 & 18 & 20 & 8 & 20 & 16 & 11 & 18 & 17 & 21 \\
\hline A & 1.000 & 1.000 & 1.000 & 1.000 & 1.000 & 1.000 & 1.000 & 1.000 & 1.000 & 1.000 & 1.000 & 1.000 \\
\hline \multicolumn{13}{|l|}{ EST-1 } \\
\hline (n) & 12 & 19 & 14 & 18 & 20 & 8 & 20 & 16 & 11 & 18 & 17 & 21 \\
\hline A & 0.000 & 1.000 & 1.000 & 1.000 & 0.000 & 0.000 & 0.000 & 0.000 & 0.000 & 0.000 & 0.000 & 0.000 \\
\hline B & 1.000 & 0.000 & 0.000 & 0.000 & 0.000 & 0.000 & 0.000 & 0.000 & 0.000 & 0.000 & 0.000 & 0.000 \\
\hline $\mathrm{C}$ & 0.000 & 0.000 & 0.000 & 0.000 & 1.000 & 1.000 & 1.000 & 1.000 & 1.000 & 1.000 & 1.000 & 1.000 \\
\hline \multicolumn{13}{|l|}{ EST-2 } \\
\hline (n) & 13 & 21 & 16 & 18 & 20 & 8 & 20 & 16 & 11 & 16 & 17 & 21 \\
\hline A & 0.000 & 0.095 & 0.188 & 0.111 & 0.150 & 0.438 & 0.200 & 0.125 & 0.182 & 0.094 & 0.353 & 0.262 \\
\hline B & 1.000 & 0.905 & 0.813 & 0.889 & 0.850 & 0.563 & 0.800 & 0.875 & 0.818 & 0.906 & 0.647 & 0.738 \\
\hline \multicolumn{13}{|c|}{ GAPD-1 } \\
\hline (n) & 13 & 21 & 18 & 18 & 20 & 8 & 20 & 16 & 11 & 18 & 17 & 21 \\
\hline A & 1.000 & 1.000 & 1.000 & 0.000 & 1.000 & 1.000 & 1.000 & 1.000 & 1.000 & 1.000 & 1.000 & 1.000 \\
\hline B & 0.000 & 0.000 & 0.000 & 1.000 & 0.000 & 0.000 & 0.000 & 0.000 & 0.000 & 0.000 & 0.000 & 0.000 \\
\hline \multicolumn{13}{|c|}{ GAPD-2 } \\
\hline (n) & 13 & 21 & 18 & 18 & 20 & 8 & 20 & 16 & 11 & 18 & 17 & 21 \\
\hline A & 1.000 & 1.000 & 1.000 & 0.000 & 1.000 & 1.000 & 1.000 & 1.000 & 1.000 & 1.000 & 1.000 & 1.000 \\
\hline B & 0.000 & 0.000 & 0.000 & 1.000 & 0.000 & 0.000 & 0.000 & 0.000 & 0.000 & 0.000 & 0.000 & 0.000 \\
\hline \multicolumn{13}{|l|}{ GPI } \\
\hline (n) & 13 & 19 & 18 & 18 & 19 & 8 & 20 & 16 & 11 & 18 & 17 & 21 \\
\hline A & 0.885 & 1.000 & 1.000 & 1.000 & 0.763 & 0.563 & 1.000 & 1.000 & 0.727 & 1.000 & 1.000 & 1.000 \\
\hline B & 0.115 & 0.000 & 0.000 & 0.000 & 0.237 & 0.438 & 0.000 & 0.000 & 0.273 & 0.000 & 0.000 & 0.000 \\
\hline \multicolumn{13}{|l|}{ LDH-1 } \\
\hline (n) & 7 & 13 & 11 & 11 & 9 & 2 & 10 & 9 & 5 & 11 & 12 & 15 \\
\hline A & 0.143 & 0.269 & 1.000 & 0.000 & 0.889 & 1.000 & 0.000 & 0.000 & 0.000 & 0.000 & 0.000 & 0.067 \\
\hline B & 0.500 & 0.731 & 0.000 & 1.000 & 0.111 & 0.000 & 1.000 & 1.000 & 1.000 & 1.000 & 1.000 & 0.867 \\
\hline $\mathrm{C}$ & 0.071 & 0.000 & 0.000 & 0.000 & 0.000 & 0.000 & 0.000 & 0.000 & 0.000 & 0.000 & 0.000 & 0.033 \\
\hline $\mathrm{D}$ & 0.286 & 0.000 & 0.000 & 0.000 & 0.000 & 0.000 & 0.000 & 0.000 & 0.000 & 0.000 & 0.000 & 0.033 \\
\hline \multicolumn{13}{|l|}{ LDH-2 } \\
\hline (n) & 7 & 13 & 12 & 11 & 10 & 2 & 11 & 9 & 5 & 11 & 11 & 15 \\
\hline A & 0.786 & 0.769 & 0.958 & 0.864 & 0.800 & 1.000 & 0.909 & 0.833 & 0.900 & 0.682 & 0.773 & 0.733 \\
\hline B & 0.214 & 0.231 & 0.042 & 0.136 & 0.200 & 0.000 & 0.091 & 0.167 & 0.100 & 0.318 & 0.227 & 0.267 \\
\hline
\end{tabular}


Appendix 1. (Continued).

\begin{tabular}{|c|c|c|c|c|c|c|c|c|c|c|c|c|}
\hline \multirow[t]{2}{*}{ Locus } & \multicolumn{12}{|c|}{ Populations } \\
\hline & KYFL & DSFL & LLA & SCTX & SPTX & MDTX & WSTX & ADTX & CDTX & VHMX & EMMX & VRMX \\
\hline \multicolumn{13}{|l|}{ MDH-1 } \\
\hline (n) & 12 & 21 & 17 & 17 & 19 & 5 & 18 & 15 & 8 & 17 & 17 & 21 \\
\hline A & 1.000 & 1.000 & 1.000 & 1.000 & 0.974 & 1.000 & 1.000 & 1.000 & 1.000 & 1.000 & 1.000 & 1.000 \\
\hline B & 0.000 & 0.000 & 0.000 & 0.000 & 0.026 & 0.000 & 0.000 & 0.000 & 0.000 & 0.000 & 0.000 & 0.000 \\
\hline \multicolumn{13}{|l|}{ MDH-2 } \\
\hline (n) & 12 & 19 & 17 & 16 & 19 & 7 & 20 & 15 & 10 & 17 & 17 & 21 \\
\hline A & 0.500 & 0.737 & 1.000 & 1.000 & 0.553 & 0.500 & 0.925 & 1.000 & 1.000 & 1.000 & 0.941 & 1.000 \\
\hline B & 0.000 & 0.000 & 0.000 & 0.000 & 0.000 & 0.000 & 0.000 & 0.000 & 0.000 & 0.000 & 0.029 & 0.000 \\
\hline $\mathrm{C}$ & 0.500 & 0.263 & 0.000 & 0.000 & 0.447 & 0.500 & 0.075 & 0.000 & 0.000 & 0.000 & 0.029 & 0.000 \\
\hline \multicolumn{13}{|l|}{ MP-1 } \\
\hline (n) & 3 & 18 & 10 & 17 & 17 & 5 & 14 & 12 & 10 & 15 & 16 & 20 \\
\hline A & 0.000 & 0.000 & 0.000 & 0.000 & 0.000 & 0.000 & 0.000 & 0.167 & 0.000 & 0.000 & 0.000 & 0.000 \\
\hline B & 0.167 & 0.000 & 0.000 & 0.000 & 0.000 & 0.000 & 0.000 & 0.000 & 0.000 & 0.000 & 0.000 & 0.000 \\
\hline $\mathrm{C}$ & 0.167 & 0.000 & 0.150 & 0.000 & 0.000 & 0.000 & 0.000 & 0.000 & 0.000 & 0.000 & 0.000 & 0.000 \\
\hline $\mathrm{D}$ & 0.667 & 1.000 & 0.850 & 1.000 & 1.000 & 1.000 & 1.000 & 0.833 & 1.000 & 1.000 & 1.000 & 1.000 \\
\hline \multicolumn{13}{|l|}{ MP-2 } \\
\hline (n) & 12 & 19 & 14 & 18 & 17 & 5 & 17 & 15 & 10 & 17 & 17 & 19 \\
\hline A & 0.000 & 0.000 & 0.000 & 0.000 & 0.000 & 0.000 & 0.000 & 0.100 & 0.000 & 0.000 & 0.000 & 0.000 \\
\hline B & 0.958 & 1.000 & 1.000 & 0.000 & 0.941 & 0.800 & 0.971 & 0.700 & 0.850 & 0.912 & 1.000 & 0.921 \\
\hline $\mathrm{C}$ & 0.000 & 0.000 & 0.000 & 1.000 & 0.000 & 0.000 & 0.000 & 0.000 & 0.000 & 0.000 & 0.000 & 0.000 \\
\hline $\mathrm{D}$ & 0.042 & 0.000 & 0.000 & 0.000 & 0.059 & 0.200 & 0.029 & 0.200 & 0.150 & 0.088 & 0.000 & 0.079 \\
\hline \multicolumn{13}{|l|}{ MPI } \\
\hline (n) & 10 & 17 & 16 & 14 & 14 & 5 & 15 & 12 & 8 & 14 & 15 & 16 \\
\hline A & 0.300 & 1.000 & 0.969 & 0.929 & 1.000 & 1.000 & 1.000 & 1.000 & 1.000 & 1.000 & 1.000 & 1.000 \\
\hline B & 0.700 & 0.000 & 0.031 & 0.071 & 0.000 & 0.000 & 0.000 & 0.000 & 0.000 & 0.000 & 0.000 & 0.000 \\
\hline \multicolumn{13}{|l|}{ NP } \\
\hline (n) & 15 & 13 & 15 & 9 & 10 & 8 & 11 & 9 & 12 & 23 & 18 & 22 \\
\hline A & 0.233 & 0.000 & 0.000 & 0.000 & 0.100 & 0.188 & 0.000 & 0.000 & 0.208 & 0.087 & 0.056 & 0.091 \\
\hline B & 0.000 & 0.000 & 0.000 & 0.000 & 0.000 & 0.000 & 0.000 & 0.000 & 0.000 & 0.087 & 0.000 & 0.000 \\
\hline $\mathrm{C}$ & 0.067 & 0.615 & 0.533 & 0.889 & 0.350 & 0.438 & 1.000 & 1.000 & 0.792 & 0.739 & 0.944 & 0.864 \\
\hline $\mathrm{D}$ & 0.700 & 0.385 & 0.467 & 0.111 & 0.550 & 0.375 & 0.000 & 0.000 & 0.000 & 0.087 & 0.000 & 0.045 \\
\hline \multicolumn{13}{|l|}{ 6-PGD } \\
\hline (n) & 13 & 21 & 17 & 16 & 19 & 8 & 17 & 15 & 11 & 17 & 17 & 21 \\
\hline A & 1.000 & 1.000 & 1.000 & 1.000 & 1.000 & 1.000 & 1.000 & 1.000 & 1.000 & 1.000 & 1.000 & 1.000 \\
\hline \multicolumn{13}{|l|}{ PPI } \\
\hline (n) & 10 & 18 & 19 & 16 & 13 & 5 & 18 & 14 & 8 & 17 & 16 & 19 \\
\hline A & 0.000 & 0.000 & 0.000 & 0.000 & 0.000 & 0.000 & 0.000 & 0.000 & 0.000 & 0.176 & 0.000 & 0.000 \\
\hline B & 0.150 & 0.028 & 0.053 & 0.000 & 0.000 & 0.200 & 0.000 & 0.000 & 0.188 & 0.000 & 0.219 & 0.184 \\
\hline $\mathrm{C}$ & 0.550 & 0.889 & 0.868 & 1.000 & 0.962 & 0.600 & 1.000 & 0.929 & 0.438 & 0.441 & 0.406 & 0.395 \\
\hline $\mathrm{D}$ & 0.300 & 0.083 & 0.079 & 0.000 & 0.038 & 0.200 & 0.000 & 0.071 & 0.375 & 0.382 & 0.375 & 0.421 \\
\hline \multicolumn{13}{|l|}{ TPI-1 } \\
\hline (n) & 12 & 17 & 18 & 15 & 12 & 4 & 15 & 12 & 9 & 17 & 17 & 18 \\
\hline A & 1.000 & 1.000 & 1.000 & 1.000 & 1.000 & 1.000 & 1.000 & 1.000 & 1.000 & 1.000 & 1.000 & 1.000 \\
\hline \multicolumn{13}{|l|}{ TPI-2 } \\
\hline (n) & 12 & 17 & 18 & 15 & 12 & 4 & 15 & 12 & 9 & 17 & 17 & 18 \\
\hline A & 1.000 & 1.000 & 1.000 & 1.000 & 1.000 & 1.000 & 1.000 & 1.000 & 1.000 & 1.000 & 1.000 & 1.000 \\
\hline $\bar{H}$ & 0.237 & 0.082 & 0.054 & 0.041 & 0.144 & 0.151 & 0.038 & 0.066 & 0.113 & 0.097 & 0.101 & 0.121 \\
\hline $\mathrm{A} / \mathrm{L}$ & 1.8 & 1.4 & 1.4 & 1.3 & 1.5 & 1.4 & 1.2 & 1.3 & 1.4 & 1.4 & 1.4 & 1.6 \\
\hline$\% P$ & 42.9 & 33.3 & 23.8 & 23.8 & 38.1 & 28.6 & 14.3 & 23.8 & 33.3 & 23.8 & 28.6 & 33.3 \\
\hline
\end{tabular}

